\title{
Against telic monism in logic
}

\section{Leon Commandeur ${ }^{1}$}

Received: 23 August 2021 / Accepted: 7 November 2021 / Published online: 25 February 2022 (c) The Author(s) 2022

\begin{abstract}
Telic monism in logic is the thesis that there is one single philosophically primary goal to logic. A different way to put it is that there is only one canonical application to logic. This thesis is widely present-implicitly or more explicitly_in the literature on the philosophy of logic, yet has not been examined nor argued for extensively. In this paper I will present and critically examine telic monism. One prominent candidate for the canonical application of logic, namely the formal codification of logical consequence in natural language, will be challenged directly. The critique will then be generalized by appealing to a practice-based philosophy of logic. The general argument I put forth here claims that we have no principled reason to assume there to be just one primary goal to logic. Rather, I claim that it is more plausible that there actually is a variety of goals, purposes and applications to logic, without one of them enjoying primacy over the others. If this argument succeeds, at least one of the consequences is that it allows for a kind of logical pluralism that has previously been deemed insignificant, namely logical instrumentalism.
\end{abstract}

Keywords Philosophy of logic · Logical pluralism · Theoretical philosophy · Practice-based approach · Telic monism · Logical instrumentalism

\section{Introduction}

Telic monism in logic ${ }^{1}$ is the thesis that there is one single philosophically primary goal to logic. A different way to put it is that there is only one canonical application to logic. This thesis is a significant claim about the nature and scope of logic, and widely present in the literature on the philosophy of logic. However, it has not been independently examined nor argued for extensively. In this paper I will present and examine telic monism, and aim to show that this thesis is implausible. If the arguments

\footnotetext{
${ }^{1}$ Throughout this paper I will only consider telic monism in logic. Henceforth, I will mainly talk just of telic monism.

$凶$ Leon Commandeur

leon.commandeur@uib.no

1 Department of Philosophy, University of Bergen, Bergen, Norway
} 
against telic monism succeed, at least one of the consequences is that it allows for a kind of logical pluralism that has previously been deemed insignificant, namely logical instrumentalism.

This paper is structured as follows. In the first section I will present telic monism and the related objection of insignificance. In the second section, I will present examples of telic monism and the objection of insignificance that can be found in the literature. In the third section, I will critically examine one prominent candidate for the primary goal or canonical application of logic, namely some version of what I will label the Primacy of Natural Language-thesis. In the fourth section, I will start aiming to show that the contrary of telic monism - namely the idea of there being a plurality of goals without one of them enjoying primacy over the other(s) - is more plausible. I will start by presenting a more general approach to counter the idea that there is one single primary goal of logic, namely a practice-based approach. In the fifth section, I will aim to show that there is what I will label a genuine plurality of goals. In the sixth section, I will briefly address a potential objection to my arguments against telic monism.

\section{Telic monism in logic}

There is a widely held assumption in the philosophy of logic that there is one goal or application to logic that is philosophically more significant or substantial than other goals or applications. ${ }^{2}$ Put differently, the assumption is that there is one particular goal or application-commonly referred to as the philosophical primary goal or canonical application of logic - that enjoys primacy over other potential goals or applications. This thesis can be labelled telic monism:

Telic monism: There is only one philosophically primary goal or canonical application of logic.

What can this goal or application be? There are various ideas on this matter. One prominent candidate for the primary goal of logic is that of a formal codification of logical consequence in natural language-something I will discuss more in-depth in Sect. 3 where I label this the Primacy of Natural Language-thesis. Cook (2010) has proposed this. A different goal, proposed by McSweeney (2018), is that of capturing the structure of mind-and-language independent reality. Yet another goal, though not explicitly defended as the sole primary goal of logic, is to model information-flow in a dynamic, multi-agent setting, as the logical dynamics program has it (Van Benthem, 2011). One could of course think of many more different goals, purposes or applications to logic. The key in understanding telic monism is that whatever one takes

\footnotetext{
2 The terms 'goal' and 'application' (and sometimes 'purpose') have (slightly) different connotations. However, they are connected to each other, especially when — as I will do here-they are used in the context of the '(philosophically) primary goal' or 'canonical application'. This connection is roughly the following: the primary goal of logic can be seen as the most important application of logic on $S$. Put differently, the canonical application of logic on $S$ might be seen as the primary goal of logic. It could be that when a logic is being employed with a specific goal in mind, unforeseen successful applications come to light. However, as we will see later in this paper, when one assumes one particular primary goal or canonical application, those unforeseen applications might be interesting in themselves, but are merely derivative, non-canonical or non-primary projects.
} 
the primary goal of logic to be, the telic monist will consider any other, non-primary goal or non-canonical application as potentially interesting and useful in itself, yet insignificant when we are considering the nature of logic. This line of thinking can be formulated in what I will label the Objection of Insignificance:

Objection of Insignificance: Everybody agrees that there are many things one could do with logic, given that there is a wide variety of successful and interesting applications of logic. However, given that there is only one canonical application or one philosophically primary goal of logic, all the non-canonical applications and nonprimary goals are potentially interesting and useful in themselves, but not interesting or philosophically significant when considering (a theory of) the nature of logic.

One might wonder why philosophers or logicians should worry about the goals, purposes and scope of logic. Here are some reasons why I take this to be a relevant issue. First of all, as a matter of observation, telic monism and the connected objection of insignificance play a significant role in the philosophy of logic. According to Allo (2017) the idea that "logical systems have a single, reasonably well-defined, privileged domain of application or most general purpose of logic" (p. 547, fn. 3) is even the majority-view. Examining to what extent this majority-view is in fact justified is an important and relevant project. However, the importance of assessing telic monism, and thereby the study of the goals and scope of logic, can also be shown by considering a particular context in which the thesis plays an important role, namely that of the debate on logical pluralism. One consequence of accepting telic monism, is that it rules out a particular kind of logical pluralism called logical instrumentalism. If the argument against telic monism made in this paper succeeds, one result is then that it has opened up the path for logical instrumentalism to be taken seriously. And if some version of logical instrumentalism is correct, the question of what goals or purposes logic can help to achieve becomes even more relevant. These observations offer reasons to closely examine and critically assess telic monism directly, something that hasn't been done so far.

\subsection{Telic monism, pluralism and instrumentalism}

The examples of telic monism that I will present in this paper are mostly taken from the debate on logical pluralism. Logical pluralism is the thesis that there are multiple different, equally correct logical systems. Although there are various different versions of logical pluralism, ${ }^{3}$ this is its core thesis. Logical monism, on the other hand, is the thesis that there is ultimately only one genuine logical system, sometimes labelled as the One True Logic. ${ }^{4}$ The idea that there is only one philosophically primary goal to logic might sound as if this implies that there is also one philosophically primary logical system. For example, if the formal codification of logical consequence in natural language is the primary goal of logic, then it might be that there is one logical system that is accurately able to do so, and hence this logical system could be regarded as

\footnotetext{
3 Examples include Beall and Restall (2006), Field (2009), Shapiro (2014) and Caret (2017).

4 Examples include Priest (2006), Williamson (2013) and Read (2006), but they all endorse different logics as the One True Logic.
} 
the One True Logic. On this reasoning, telic monism would entail logical monism. However, this reasoning is wrong. Telic monism is compatible with both logical pluralism and logical monism. One might hold that there are various logical systems that achieve one goal, where each system provides us different perspectives (Cook, 2002; Shapiro, 2014).

Telic monism and logical pluralism are strictly speaking distinct issues. However, taking examples from the debate on logical pluralism can help us give a better idea of what is at stake when considering telic monism. The reason for this is that the thesis is often employed in this debate, mostly to rule out a particular kind of logical pluralism, namely logical instrumentalism. In short, logical instrumentalism is the idea that logic is best understood as a tool or instrument to achieve particular goals, that the 'correct' logical system is relative to a particular goal, purpose or application, and further assumes that there is a plurality of such goals, purposes and applications (Kouri Kissel, 2019). What sets logical instrumentalism apart from telic monism is that although both acknowledge the fact that logic can be used for various purposes, logical instrumentalism stops short of privileging one particular purpose over the others. As Kouri Kissel (2019) writes:

[T]hough most people will agree that logic is a tool, they think that there is something additional to certain logic(s) which makes them more fundamental, more basic, or "righter". Logical instrumentalism stops short of this (p. 154).

This can be read as the instrumentalists reply to the objection of insignificance, where telic monism can be seen as taking certain logic(s) to be more fundamental, more basic, or "righter" because they contribute to achieving the primary goal or canonical application to logic. The logical instrumentalist disagrees with the telic monist. As Kouri Kissel (2019) writes:

The logical instrumentalist cannot hold that there is a canonical application of logic. The instrumentalist must in fact reject that there is such a canonical application, otherwise she will undercut her own position (p. 155).

Therefore, for logical instrumentalism to be a viable position in the philosophy of logic, we first have to establish that the instrumentalist is able to reject telic monism. The aim of this paper is to show that the latter can be done. Moreover, if logical instrumentalism is correct, i.e. that logic is indeed best understood as a tool or instrument to achieve particular goals, it raises the question precisely which goals logic is able to help achieve. It is out of the scope of this paper to provide a complete and conclusive answer to this latter question, but it does suggest-via the practice-based approach-a method of how we can select these goals, namely by taking seriously the actual scientific practice of the logical community, which would prohibit philosophers to settle on what exactly the goals of logic are entirely independent of the actual, diverse scientific practice. ${ }^{5}$

\footnotetext{
5 At the same time, one might also argue that it is philosophers of a specific field $F$, such as logic, that are in the business of critically analyzing $F$, whereas practitioners in $F$ are not. Still, however, I take it that the philosopher of $F$ cannot—or: should not—do so entirely independent of the actual practice of $F$.
} 


\section{Telic monism at work}

In this section I will present some examples of telic monism and the objection of insignificance that can be found in the literature, in order to see telic monism at work.

The first example will be that of Cook (2010). According to Cook, if logical pluralism is to be significant and substantial, it has to avoid relying on anderlying relativism. A pluralism that relies on some underlying relativism Cook labels dependent pluralism. The issue with dependent pluralisms, according to Cook, is that they are mostly trivially true. Consider the following example of logical pluralism labelled Philosophical Logical Pluralism* (PLP*): ${ }^{6}$

PLP*: The correct logic (relative to the goals of applied mathematics, or the goals of philosophical logic) is relative to the (linguistic) phenomenon being represented.

Cook argues that such a kind of pluralism is trivially true, and thus insignificant, given that while anyone can agree that there have been many different applications to logic, such as "electronic circuit design, database management, and internet security" (p. 494):

[t]he idea [is] that the philosophically primary (but obviously not only) goal of logical theorizing is to provide a formal codification of logical consequence in natural language (p. 495).

This is an instance of the objection of insignificance, acknowledging that there are many goals, purposes and applications to logic, but at the same time hold that the allegedly non-primary goals of logic are being distinguished from the one primary goal of logic. Thus, various other applications of logic are considered as potentially interesting and useful in themselves, yet essentially different, derivative projects and of lesser philosophical significance.

There are two points worth raising here with respects to Cook's articulation of telic monism. First of all, it is unclear what is precisely meant by the term philosophically primary: what does it mean for some goal or application to be philosophically primary? One way to understand this notion is by taking it to be the goal or application that has traditionally been considered to be the most important or interesting goal or application of logic by philosophers, the one that has perhaps generated interest in logic in the first place by philosophers. Such an understanding is, however, not neutral, for it aims very specifically for the primary goal of one particular field where logic is being used, namely that of philosophy. This would disregard various other fields where logic is currently being used in, such as computer science or computational linguistics. But even so, it is not obvious that even specifically for the field of philosophy there is only one primary goal, as we will see when the next example is presented below. And when assuming that there are various goals even specifically in the field of philosophy, there is still the question how we exactly are to pick the most important goal or application.

\footnotetext{
${ }^{6}$ (PLP*) looks fairly similar to logical instrumentalism: a logic is 'correct' only relative to a particular application.
} 
A second point worth raising is the following. As Cook recognizes, while the truth of the claim that there is a plurality of applications is obvious, the triviality of this truth need not be. We only need to take in consideration the history of logic-and the absence of logics applied successfully to such a wide variety of phenomena- to see that this it is not obvious that logics can be applied to such a wide variety of phenomena. I consider this noteworthy: the fact that the historical absence of logics applied to phenomena we now consider to be fruitfully represented by logic could show that we have gained some significant insights in the nature, scope and workings of logic. From Cook's presentation, it appears to be that he disagrees and that despite this actual plurality of applications, the (philosophically) primary goal of logic is restricted to only the formal codification of logical consequence in natural language. The problem is, however, that Cook has not provided a principled reason to lend primacy to one particular goal among a plurality of goals, and neither has he provided an argument for why that particular goal should have this primacy. As such, his telic monism remains without further justification.

The second example can be found in McSweeney (2018). Here, McSweeney discusses metaphysical logical realism as one way to argue for a particular One True Logic. She first displays a version of the objection of insignificance when she writes:

We use all sorts of logics in specific arenas (e.g. we use fuzzy logic to program rice cookers), but we don't think that fuzzy is the [One True Logic], even if it is right to think of it as true of rice cooker programming. So we really need the [One True Logic] to be the logic that correctly captures whatever it is that we think logic is for. In order for it to make sense to think that there is [One True Logic], we need to think that logic has a unique purpose or goal (p. 2).

Cook's electronic circuit design, database management, and internet security have been replaced here by a rice cooker. Other than that, the argument runs similarly, although McSweeney moves on to propose, on the metaphysical logical realists' behalf, a different unique purpose to logic than Cook:

We clearly aren't trying to only get at the nature and function of rice cookers with our logic, and that is why fuzzy logic is not the [One True Logic]. But what are we trying to do? [...] The metaphysical logical realist thinks: logic is for capturing the structure of mind-and-language independent reality (p. 2).

Let's briefly pause to make note of the following observations. First, while Cook employs telic monism in a defense for logical pluralism, McSweeney does so in a defense for logical monism, thus showing that telic monism can be held by both logical pluralists and logical monists. Second, the unique primary purposes of logic that Cook and McSweeney put forth are radically different. For Cook the unique primary purpose of logic is that of the formal codification of logical consequence in natural language, while for McSweeney it is that of capturing the structure of mindand-language independent reality. ${ }^{7}$ This observation makes it clear that it is important

\footnotetext{
7 This reflects what Hjortland (2019, p. 254) considers to be a key-divide among theories about logical properties, namely between those taking logical properties to be metalinguistic and those taking these to be non-metalinguistic.
} 
for any telic monist to provide a principled reason as to why we should consider one particular goal as the primary goal.

The third example can be found in Priest (2006). Priest makes a distinction between pure and applied logics. A pure logic is nothing more than a "well-defined mathematical structure with a proof-theory, model theory, etc." (p. 195). An applied logic is simply a pure logic applied - or: interpreted - in some particular way, and then the logic "becomes a theory of how the domain in which it is interpreted behaves". Priest first acknowledges that there are various things that we can do with logic, when he writes that

pure logics can be applied for many purposes, such as simplifying electronic circuits, or analyzing certain grammatical structures. And again, it is clear and uncontentious that different pure logics may be appropriate for each application (p. 196).

However, Priest further argues that ultimately there is only one application, the canonical application, that is of real interest. He thereby displays a version of the objection of insignificance: although there are many different applications for a pure logic, what we should ultimately be interested in is the canonical application, which Priest describes as "the most important and traditional application of a pure logic" (p. 196). Priest moves on to argue that the canonical application of logic is "the application of a logic in the analysis of reasoning", where "[ $t]$ he central purpose of an analysis of reasoning is to determine what follows from what-what premises support what conclusions-and why" (p. 196).

There are three noteworthy observations. First of all, given that Priest's canonical application of logic as the analysis of reasoning (in the vernacular) has similarities with Cook's primary goal of logic as a formal codification of logical consequence in natural language, as both have in mind as the most important application of logic some link between formal logic and (some particular use of) natural language, it is thereby also significantly different than McSweeney's primary goal of logic. Second, according to Priest the canonical application of logic is "the most important and traditional application of a pure logic". Just as I have commented on Cook, it is not clear how we should understand this. How exactly are we to decide what the most important application is, for example? In Sect. 5 I will present various ways to understand 'canonicality' in this context, but in anticipation of that discussion, here are some worries. It might seem that we can find the canonical application by observing what philosophers and logicians have applied (pure) logic on traditionally, but why should a traditional application be given primacy over novel applications? For one, this seems to assume that the goal, application or purpose of logic is somehow fixed in a specific time in the history of logic. If that is how we are to understand the primacy of the traditional application, it would certainly give an unfair advantage to novel applications. Furthermore, if the canonical application or primary goal is considered to be one along the lines of Cook, Priest, and McSweeney, then it is also ahistorical given that there have been various different important projects in the history of (the philosophy of) logic that had limited or no connection to either natural language, reasoning in the vernacular or a mind-and-structure independent reality-a point I will briefly come back to in Sect. 4 . 
Priest actually provides us more as to how we are to understand canonicality, when he proposes a practice-based approach to identify a canonical application. I will discuss this approach in more detail in Sect. 5.

Let me at this point briefly summarize. I have presented three examples from the literature that display versions of telic monism and the related objection of insignificance. This has showed that, first of all, telic monism can be held by both logical pluralists (such as Cook) and logical monists (such as McSweeney and Priest). Second, we have seen that there are at least three different proposals as to what the primary goal or canonical application of logic is. Along the lines, I have already provided some critique on telic monism, which can be summarized as follows. First of all, a principled reason to lend primacy to one particular goal over other goals of logic is needed but is currently lacking. Second, related to the first point, current proposals as to what the primary goal or canonical application of logic is can be challenged not only by pointing out the lack of a principled justification, but also on grounds of ahistoricality.

\section{The primacy of natural language}

There is an often-recurring answer to the question of what the philosophically primary goal or canonical application of logic is, and that is one that ascribes primacy to the connection between the formal notion of logical consequence and its informal counterpart in natural language. Call this thesis the primacy of natural language thesis:

Primacy of Natural Language thesis: the philosophically primary goal or canonical application of logic is to provide a formal codification of logical consequence in (some particular use of) natural language.

Of the previously presented examples of telic monism both Cook and Priest could be considered as endorsing versions of the primacy of natural language thesis. Cotnoir (2018) also present this thesis:

What do logics represent? It is clear from the various uses of applied logic, they can represent many different sorts of phenomena. But for the purpose of traditional logic, though, theories of consequence are frequently taken to represent natural language inference. (p. 302)

\section{A final example is Payette and Wyatt (2018):}

[I]t is only when logics are understood as theories of a consequence relation in natural language that the debates between logical monists and logical pluralists make sense: for any logics to be correct there has to be something that they are correct with respect to. Following Priest (2014), we call this the canonical application for logic (p. 278).

Given that this is a prominent candidate for the primary goal or canonical application of logic, it is worth explicitly considering this particular thesis.

Recall that Cook writes, in agreement, that "[t]he idea [is] that the philosophically primary (but obviously not only) goal of logical theorizing is to provide a formal codification of logical consequence in natural language" (p. 495). This is the claim that I will aim to problematize in the following. 
There are three ways to challenge the primacy of natural language thesis. First, one could challenge the significance of the project as a whole. Second, one could argue that it is ahistorical. Third, one could problematize the connection between the formal logical consequence relation and its informal counterpart in natural language.

The first approach can be found in Eklund (2017). He identifies three projects that could be seen as motivating some kind of logical pluralism. One of these is the actual language project, which is concerned with how our actual language is like in relevant aspects-“[w]hat can be and is expressed in our actual language?" (p. 2). Success in this project involves accurately representing our actual, natural language. In assessing the significance of this project, however, Eklund argues that although it is obviously very interesting to understand what can and is expressed in our actual language, there is no guarantee that what is expressed in our actual language really is metaphysically or normatively most important or most interesting. Thus, he considers this kind of project to be "not clearly of great philosophical interest" (p. 4).

A different way to challenge the project that underpins the primacy of natural language thesis as a whole, is to argue that it is ahistorical - an issue already touched upon in the above. Prominent figures in the history of logic were not primarily interested in a formal codification of logical consequence in natural language. Much of Frege's project was precisely motivated by overcoming the inadequacies and imprecision of natural language, just as Carnap's project. Similar arguments can be made for Aristoteles and Kant, and undoubtedly many others. If we are to truly endorse the primacy of natural language thesis, we would have to hold that these prominent figures in the history of logic were merely working on derivative projects in logic, or that figures like Frege and Carnap were not proper logicians-but surely nobody would hold this view. This is a good, historical reason to drop the latter thesis. Given the variety of projects in the history of logic the argument from ahistoricality can be applied against other proposed primary goals as well.

A third approach to challenge the primacy of natural language thesis is to problematize the connection between the formal logical consequence relation and its informal counterpart in natural language. We find a source for this approach in Glanzberg (2015), as he challenges the idea that what we find in natural language is something like a logical consequence relation, unless we drastically abstract and idealize away from natural language. Glanzberg's object of study is similar to what we've labelled the primacy of natural language thesis: the idea that "[a] natural language, as a structure with a syntax and a semantics, [...] determines a logical consequence relation" (p. 75). He aims to show that this thesis if false. Importantly for our purposes, Glanzberg does not go so far as to argue that no application of logical methods to natural language can be of any use. Clearly, there has been great success in the application of formal logical methods to natural language, but, Glanzberg writes, "the two sets of facts are fundamentally autonomous" (p. 72).

What this brief discussion aims to show is not that the project of providing a formal codification of logical consequence in (some particular use of) natural language has no place in logic at all. Rather, the claim is that there appears to be no principled reason to argue that this is the primary goal or canonical application of logic. In other words, the claim is that this project has only limited significance. Applying logical methods and systems to natural language could be an interesting and useful application 
of logic, but we have seen no reason to consider this to be the unique, primary goal or canonical application of logic. Given our considerations in the above about the limited significance of the project as a whole more generally, and the problematic connection between the formal logical consequence relation and its informal counterpart in natural language more specifically, it is actually highly implausible that this is the one primary goal of logic if there would be one.

\section{A general strategy: the practice-based approach}

Even if I have successfully disregarded the primacy of natural language thesis, it might still be that there is a different unique primary goal or purpose to logic. After all, we have seen McSweeney (2018) providing a radically different unique primary purpose to logic. Rather than contending every single proposed primary purpose, it will be useful to provide a general strategy. To do that, I will consider a general strategy of how we could potentially find the canonical application-if there is one. If this general strategy points us in a direction away from telic monism, then the prospects for the latter might be slim.

At the outset of providing such a general strategy, some terminology has to be cleared up and some assumptions will have to be stated. First of all, what exactly is meant by 'logic'? According to Caret (2021) the term 'logic' is ambiguous in at least three ways. It can refer to, first, a particular topic, second, an interdisciplinary line of research, and third, a mathematical toolbox that is widely used in that line of research. However, I take it to be that what logic is about, say: its topic, cannot be considered in complete isolation of the actual practice carried out by logicians. Therefore, I argue that the most fruitful way of finding out what logic is about, is to consider precisely the practice of logicians and the way logic, as a mathematical toolbox, is actually being put to use. In a slogan, one might say that ultimately, logic is what logic does. This idea is at the basis of a broadly practice-based approach to the philosophy of logic. A key-principle for this approach is the charity-principle: we ought to take the practice of those who the logical community commonly regards as proper logicians initially at face value. More generally, the idea is that experts within a field $F$ are reliable guides to what constitutes $F$. Several others in the philosophy of logic have suggested a broadly practice-based approach. For example, a practice-based approach to the epistemology of logic has been proposed by Martin (2020) as a way of identifying what constitutes evidence for a logical theory. Dutilh Novaes (2012a) also considers a practice-based philosophy logic, writing that such an approach "takes as its starting point logic as it was and is actually practiced-recent developments as well as its history" (p. 76).

Importantly for my purposes here, it is worth noting that Priest (2006) appears to propose a kind of practice-based approach to establishing canonicality. In presenting his strategy I will be clearing up what I understand by the notion of 'canonicality'. As we have seen in the above, Priest at one point characterizes the canonical application as "the most important and traditional application of a pure logic" (p. 196). On the face of it, it would then seem that we can find the canonical application by observing what philosophers and logicians have applied (pure) logic on traditionally. Such an 
approach appears to be in line with a common understanding of canonicality understood as part of a canon of applications of logic, where by canon we would understand a set of historically important applications of logic. ${ }^{8}$ But such an understanding seems to assume that the goal, application or purpose of logic is somehow fixed in a specific time in the history of logic. If that is how we are to understand the primacy of the traditional application, it would certainly give an unfair advantage to novel applications. Moreover, given the argument of ahistoricity put forth in the above, however, if Priest is to mean this interpretation of canonicality - and if that is indeed how we are to understand canonicality - then telic monism is plainly false, for the history of logic has shown a wide variety of applications to logic, and it is implausible to take the canon of applications of logic to be reduced to merely one canonical application. A related historical understanding of canonicality might take the initial application to be the canonical application. However, first of all, there is no guarantee that that particular application is the philosophically or conceptually most significant or interesting one, and second, it makes progress in a specific domain of science practically impossible. Similar to other sciences, like chemistry and alchemy, logic as a science has moved on since its beginnings, and we should not simply assume that the study of logic takes the same form and aims for the same goals as it had over 2000 years ago. ${ }^{9}$ But then, how are we to understand 'canonicality'? At another point, Priest (2006) writes that "[t]o give a theory canonical application, it is crucial that we forge some link between it and the practices that give the application life" (p. 169). This is consistent with the claim that the canonical application is "the most important and traditional application of a pure logic", but only when we consider traditional practices, something I have argued in the above to be too restricted. Once we allow ourselves to consider not only traditional practices, but practices both past and present (and future, for that matter) - as we have seen in the above Dutilh Novaes suggests-we will end up with the broadly practice-based approach sketched in the above.

Various arguments can be given in favor of such a practice-based approach, and although a complete case for the approach will have to be made elsewhere, I will briefly mention two here. First of all, it is an appealing, metaphysically lightweight, naturalistic theory of logic. Second, it offers a 'flexible' conception of logic that allows us to account for current logical practice without imposing anterior constraints, i.e. it is not theory-laden at the outset. In extension to the second point, I take it that logicians currently already act according to the charity-principle. When, say, a proponent of classical logic disagrees with a proponent of intuitionistic logic, neither of them will likely accuse the other of not doing logic. They could of course argue that their opponent might be doing the same-namely: logic_-but that she is simply wrong about, for example, which logic is the correct logic. What matters here, however, is that although they disagree on certain matters, they share an intuitive conception of what constitutes proper logical practice. More can be said about exactly what constitutes logical practice or what this shared intuitive conception of logical practice is. If my argument against telic monism succeeds, then it cannot be that what constitutes logical

\footnotetext{
8 Just as, for example, the canon of Dutch literature is a set of literary works that is deemed most significant or important. Thanks to Evelyn Erickson for pointing out this understanding of canonicality.

9 Thanks to Ben Martin and one referee for pressing this point.
} 
practice is a single, shared goal or application, although it might still be a particular set of goals or applications. An alternative view is that it is not the particular goal(s) or application(s) that constitutes logical practice, but a particular methodology (Sagi, 2021). Whatever the truth of the matter may turn out to be, as a working assumption I here assume that there is an intuitive, pre-theoretical, shared conception of what constitutes proper logical practice within the loosely delineated logical community, and argue that current debates in logic show this to be the case at least at a minimal level.

When adopting a practice-based approach to logic the question of what, if any, the (single) primary goal or canonical application of logic is becomes a partly empirical question, in the sense that it takes as data the actual goals that logicians have or applications to which logic has been successfully put to use by logicians. Particular philosophical doctrines about the aim of logic might then conflict with what is being observed in actual practice. ${ }^{10}$ In fact, I take this to be an important insight gained in discussing telic monism, where a staunch telic monist chooses to hold on to a preconceived idea of the purpose of logic despite conflicting data-points from actual practice. How can such a conflict be resolved? First, the arguments made by the telic monist in favor of one particular primary goal might be critically assessed. This is what I have aimed to do in the above for the primacy of natural language. But, second, it could be argued - as the practice-based approach does - that such a conflict simply cannot be resolved when we don't take the data-points offered by actual practice seriously. This can be seen as another aim of this paper. A next challenge, then, is to try to reconcile the set of philosophical doctrines about the aim of logic with the actual practice. The aforementioned logical instrumentalism can be considered as taking up exactly this challenge in that, by means of a rational reconstruction, it is argued that the nature of logic is such that it is best understood as a tool or instrument to achieve a variety of goals.

These, then, are the underlying assumptions that are at the core of the general strategy to argue against telic monism. First of all, by 'logic' I mean the work that is being done by those who are commonly regarded as proper logicians, i.e. the logical community. Second, the practice-based approach argues to take seriously as data-point the actual practice of this logical community, which makes the question of what, if any, the primary goal or canonical application of logic is a partly empirical matter. The underlying morale is that logic is what logic does and that we should not want to place anterior constraints on what we take to be proper logic, nor restrict ourselves by considering merely traditional practices. These assumptions are justified on the basis of their naturalistic footing and their respecting actual logical practice, both past and present.

In the following, I will apply a practice-based approach to identify what, if any, could be the primary goal or canonical application of logic. That involves considering actual logical practice, and identifying the goals, purposes and applications of those who we commonly regard as proper logicians, in order to see if there is one single primary goal to logic, or whether there is actually a plurality of different goals, purposes and applications to logic without one enjoying primacy over the others.

\footnotetext{
10 Thanks to one referee for pressing this point.
} 


\section{A genuine plurality of goals}

In the above I have already mentioned three goals of logic. First, there is the formal codification of logical consequence in natural language as presented by Cook and Priest, which I have discussed under the label of the primacy of natural language thesis. Second, there is McSweeney's goal of capturing the structure of mind-andlanguage independent reality. Third, I have briefly mentioned the goal of the logical dynamics program as put forth by Van Benthem (among others), namely to model information-flow in a dynamic, multi-agent setting. I will take these three examples to show that there is a genuine plurality of goals, and in order to do that I have to show three things. First, that these three goals are different goals. Second, that these three goals, even if they are essentially different, cannot be reduced to one another. By that I mean that I have to show that it is not the case that when having achieved goal $A$, you thereby have also achieved goal $B$ (but not the other way around), for it then would be the case then goal $A$ would have a privileged status. Third, I have to show that not one of the goals (naturally) enjoys primacy of the other. That is, it has to be shown that even if the goals are different, and even if the goals cannot be reduced to one another, that there still is not one goal that somehow is more fundamental than the others. ${ }^{11}$

In order to carry this out, I will be considering the three examples I have used throughout this paper, and show that they indeed cannot be reduced to one another. First, it is, at least prima facie, easy to establish that the goals that I have presented here are different. To start off, we can compare the goal of a formal codification of logical consequence in natural language with that of capturing the structure of mindand-language independent reality and observe that the former is concerned with a language-dependent reality, while the latter is explicitly concerned with a language independent reality. This represents what Hjortland (2019) takes to be a key divide in logical theories, namely one between metalinguistic theories and non-metalinguistic theories:

Metalinguistic theories hold that validity is a property of language. [...] In contrast, non-metalinguistic theories claim that validity is ultimately a property of the non-linguistic world (p. 254).

Although there is more to discuss on the metaphysics of information, it appears to be that to model information-flow in a dynamic, multi-agent setting is also not a goal that is concerned with a mind-and-language independent reality, given that it concerned with agents and the interactions amongst them. Now, prima facie, to model information-flow appears to be distinct from providing a formal codification of logical consequence in natural language. As it turns out, however, things get a bit trickier here. This leads us to the next element of the genuine plurality: that the goals cannot be reduced to one another.

\footnotetext{
11 Hlobil (2020), in a critique of abductivism about logic, aims to do something similar. He presents different conceptions of logic. By doing so one might take him to also showcase a plurality of goals and applications to logic, that are essentially genuinely different projects that cannot be reduced to one another. If Hlobil is right that there are these different conceptions of logic with irreducible goals, then that would already show that there is a genuine plurality of goals, thereby making telic monism highly implausible.
} 
Here is a line of reasoning that aims to show that the goal of modelling informationflow can be couched in terms of natural language. The informational tasks performed by intelligent interacting agents of the logical dynamics program are ultimately carried out in natural language, and hence the logical dynamics program merely studies a particular use of natural language. We might take Priest (2006) to provide this kind of reasoning more generally applied: given that all our reasoning takes place, in the first place, in the vernacular, the canonical application of logic is the analysis of reasoning in the vernacular, and thus of arguments in the vernacular. If this line of reasoning is correct, then the goal of modelling information-flow collapses into one of modelling natural language. I will provide two brief replies to this line of reasoning, aiming to show that this is not (necessarily) the case. As I take it obvious that, given the clear distinction, the goal of providing a formal codification of logical consequence in natural language cannot be reduced to goal of capturing the structure of mind-andlanguage of reality, I will merely focus on the question whether the goal of modelling information flow and that of a formal codification of logical consequence in natural language can be reduced to each other.

First, Van Benthem (2014) examined "two often disjoint streams of research: the logical semantics and pragmatics of natural language and dynamic logics of general information-driven agency" (p. 367). The goal of providing a formal codification of logical consequence in natural language can be seen as a goal within this first stream of research, while the modelling of information-flow in a dynamic, multi-agent setting can be seen as a goal of the latter stream of research. From Van Benthem's analysis it becomes clear that these are essentially two different things, focusing on different phenomena. In short, some differences are that while the object of study for the natural language project is static, the object of study for the logical dynamics project is, as the name suggest, dynamic. And while the object of study for the natural language project contains no occurrence of agents, the object of study for the logical dynamics project does. Van Benthem concludes his analysis stating that both streams of research can be of mutual benefit to each other, ${ }^{12}$ but that a reduction of the one into the other is not straightforward.

This is to argue that the goal of modelling information-flow cannot be reduced to goal of modelling some aspects of natural language, simply because these are essentially two different phenomena. If we have successfully modelled information-flow between multiple agents, we haven't thereby successfully modelled logical consequence in natural language, and the other way around.

A second reply is to point out that this reduction of goals assumes, as Dutilh Novaes (2012b) presents it, that "to describe a given target phenomenon, a formal language or formalism makes a detour via ordinary language discourse about the target phenomenon in question" (p. 99). This is an attractive idea in the context of information-flow in a multi-agent setting, given that the communication between those agents, at least in much of the examples that the logical dynamics program usually presents, is done in natural language. However, according to Dutilh Novaes, a more fruitful way to think about formal languages as models is one that omits this detour

\footnotetext{
12 "Semantics and pragmatics may profit from a rich general view of the linguistic process and its agents, but just as well, logics of agency might pay more attention to state of the art semantics and pragmatics of the linguistic expressions that accompany and guide human behavior" (Van Benthem, 2014, p. 380).
} 
via ordinary language, and rather directly aims to model a specific phenomenon. This phenomenon can of course be natural language, ${ }^{13}$ but it could also be informationflow. The proof that this can be done is given by the logical dynamics program, where no systematic analysis of natural language is given, but rather one of information and information-flow. Given that we have established, in the above, that these are two different phenomena, we have thereby provided support to the claim that modelling information-flow need not be couched in terms of natural language, and thus that a reduction of goals is not inevitable, if not implausible in this case.

That leaves us with the question as to whether one of the goals naturally enjoys primacy over the others, something that has to be the case for telic monism to hold. The fact of the matter here is that the burden of proof is on the telic monist. In this paper, we have seen Cook (2010) argue for a philosophically primary goal, but I have aimed to show that it is unclear what a philosophically primary goal would be, or in particular why the formal codification of logical consequence in natural language would be the philosophically primary goal. McSweeney's (2018) goal of capturing the structure of mind-and-language independent reality might have a certain appeal for lending primacy to, given that it is aimed at some ultimately reality, arguably the most fundamental it can get. As such, this might be perceived as a goal that naturally enjoys primacy over the others. However, it is not, for the simple reason that capturing the structure of mind-and-language independent reality is only of interest if you are interested in some mind-and-language independent reality. That is of course an interesting goal, but its logic might be completely useless for those interested in human reasoning or natural language. The telic monist should not just stipulate a particular primary goal: a principled reason as to why that goal should have primacy over the others should be provided. For the examples given here, I cannot find such a principled reason. I grant that absence of evidence is not evidence of absence, and one could also argue that the fact that people might disagree over what the primary goal or canonical application of logic is does not constitute evidence that there is no such goal or application. However, my argument is that until such a principled reason has been provided, telic monism is implausible. Even more, the practice-based approach to logic as outlined in this paper can be seen as a direct argument against telic monism.

\section{Concluding remarks}

So far I have presented, examined and ultimately argued against telic monism in logic. In doing so, via the practice-based approach, I have put forth an argument to allow for a widening of the scope of logic. At this point, some might object that I am stretching the nature and scope of logic too far. Having one philosophically primary goal or canonical application of logic could potentially function as (part of) the demarcation of logic. It makes sure we are keeping things within bounds. If logic is to be something unified, the primary goal or canonical application might be just (part of) what unifies it. Refusing the existence of one philosophically primary or canonical application to logic makes logic fundamentally disunified. The feeling that gives rise to such an

13 Cf. Dutilh Novaes (2012b, p. 100, fn. 58). 
objection might be something as described by Van Benthem (2008)_in only a slightly different context—as follows:

There is a general feeling that [logic] is broadening its scope and agenda beyond classical foundational issues, and maybe even a concern that, like Stephen Leacock's famous horseman, it is 'riding off madly in all directions' (p. 182).

Letting go of telic monism might just be the letting go of the reins of our horse, or so the objection might be.

There can be various replies to this objection. First, it is not obvious that logic is unified by its goals or applications. Another option, as I have suggested in the above, is that logic is unified in its method, rather than in its goals and applications (Sagi, 2021). Second, it is indeed true that my critique of telic monism allows us to significantly broaden the nature and scope of logic. However, we might just have to bite this bullet, given that the broadening is justified via the practice-based approach to the philosophy of logic that I have suggested here. If actual practice shows a wide variety of goals and applications to logic, and if we have no principled reason to consider one of those as primary or canonical, then this broadening can simply be seen as a result that we cannot deny merely on the grounds that it does not fit a specific, predetermined, fixed conception of logic.

This raises another question: how flexible should our conception of the nature and scope of logic be? More concrete, the question is if any goal would be allowed under such a conception as I am suggesting here. One might think that some goals should not be considered: for example, logic will obviously not help you if your goal is to learn how to ride a bike or how to grow a bonsai-tree. Surely, some goals should be considered illegitimate-but which ones and how are we to decide? In the context of this paper, and more precisely on the practice-based approach as presented here, there is an easy answer available: the appropriate goals are selected by those who the logical scientific community commonly considers to be proper logicians. This reply does raise further questions as to how we are to demarcate the relevant community and by what standards we take someone to be a 'proper logician'. Also, it avoids the question of why these goals are selected by these proper logicians. What is it that makes some goals appropriate for logicians, but other goals not? In this paper I have avoided discussing these questions in depth, resorting to an intuitive shared conception of what constitutes logical practice. But ideas about what constitutes logical practice might in fact differ. For example, if logic is taken to be the study of reasoning, then it might be ordinary language users who constitute logical practice, where the logician 'merely' resorts to facts found in cognitive psychology (on intuitions about validity) or linguistics (on the grammatical structure of valid arguments). Although such datapoints might be considered in logical theorizing, I take it to be that logicians are generally not considered to be cognitive psychologists or linguists in disguise. This is one of the reasons why I take it to be more reasonable, as a starting point, to consider logical practice to be constituted by those who the loosely delineated logical community commonly regards as proper logicians. ${ }^{14}$ Questions like how exactly how we are to demarcate 'proper logicians' and 'proper goals of logic' will need to be

\footnotetext{
14 As one referee put it, "Was Turing a logician?". Depending on what the telic monist takes to be the primary goal or canonical application, a similar question could be asked for various other authors in (the history
} 
answered, but for the time being I believe that we can rely on our confidence in the scientific community as a 'self-filtering system' that filters out the non-logicians and the bad, irrelevant and uninteresting goals for us.

Acknowledgements I would like to thank Ben Martin and Ole Hjortland for their patience and immensely valuable guidance in all the phases this paper has been through. I would also like to thank the members of the Bergen Logic Group for useful comments, advice and questions on an earlier draft of the paper, and the organization and audience of the Human and Social Aspects in Logic workshop at Paderborn University for letting me present the paper and for providing valuable feedback. Specifically, I would like to thank Robert Passmann, Evelyn Erickson and Sebastian Sequoiah-Grayson for providing me with much-appreciated suggestions and feedback on various drafts of the paper.

Funding Open access funding provided by University of Bergen (incl Haukeland University Hospital). Research funded by the University of Bergen.

\section{Declarations}

Conflict of interest The author declare that there is no conflict of interest.

Data availability Not applicable.

Code availability Not applicable.

Consent to participate Not applicable.

Consent for publication Not applicable.

Open Access This article is licensed under a Creative Commons Attribution 4.0 International License, which permits use, sharing, adaptation, distribution and reproduction in any medium or format, as long as you give appropriate credit to the original author(s) and the source, provide a link to the Creative Commons licence, and indicate if changes were made. The images or other third party material in this article are included in the article's Creative Commons licence, unless indicated otherwise in a credit line to the material. If material is not included in the article's Creative Commons licence and your intended use is not permitted by statutory regulation or exceeds the permitted use, you will need to obtain permission directly from the copyright holder. To view a copy of this licence, visit http://creativecommons.org/licenses/ by/4.0/.

\section{References}

Allo, P. (2017). A constructionist philosophy of logic. Minds \& Machines, 27, 545-564. https://doi.org/10. 1007/s11023-017-9430-9

Beall, J. C., \& Restall, G. (2006). Logical pluralism. Clarendon. https://doi.org/10.1093/acprof:oso/ 9780199288403.001.0001

Caret, C. R. (2017). The collapse of logical pluralism has been greatly exaggerated. Erkenntnis, 82, 738-760. https://doi.org/10.1007/s10670-016-9841-7

Footnote 14 continued

of) logic. In this paper, I have briefly mentioned Frege and Carnap as two figures who on one particular understanding of the primary goal of logic might not have been proper logicians - a position I think nobody would hold. The answer to such questions, on the practice-based approach I'm advocating here, is that it is out to the logical community-experts within the field of logic - to decide on these matters. I trust that the logical community would indeed count Turing, Frege and Carnap as logicians, despite their different projects. To what extent such an answer is satisfactory depends on the extent to which the practice-based approach to logic as presented in this paper is a plausible one. 
Caret, C. R. (2021). Why logical pluralism? Synthese, 198, 4947-4968. https://doi.org/10.1007/s11229019-02132-w

Cook, R. T. (2002). Vagueness and mathematical precision. Mind, 111(442), 225-247.

Cook, R. T. (2010). Let a thousand flowers bloom: A tour of logical pluralism. Philosophy Compass, 5(6), 492-504. https://doi.org/10.1111/j.1747-9991.2010.00286.x

Cotnoir, A. J. (2018). Logical nihilism. In J. Wyatt, N. J. L. L. Pedersen, \& N. Kellen (Eds.), Pluralisms in truth and logic (301-302). Palgrave Macmillan. https://doi.org/10.1007/978-3-319-98346-2_13.

Dutilh Novaes, C. (2012a). Towards a practice-based philosophy of logic: Formal languages as a case study. Philosophia Scientice, 16(1), 71-102. https://doi.org/10.4000/philosophiascientiae.719

Dutilh Novaes, C. (2012b). Formal languages in logic. Cambridge University Press. https://doi.org/10.1017/ CBO9781139108010

Eklund, M. (2017). Making sense of logical pluralism. Inquiry, 63(3-4), 1-22. https://doi.org/10.1080/ 0020174X.2017.1321499

Field, H. (2009). Pluralism in logic. Review of Symbolic Logic, 2(2), 342-359. https://doi.org/10.1017/ S1755020309090182

Glanzberg, M. (2015). Logical consequence and natural language. In C. Caret \& O. Hjortland (Eds.), Foundations of logical consequence (71-120). Oxford University Press. https://doi.org/10.1093/acprof:oso/ 9780198715696.003 .0003$.

Hjortland, O. T. (2019). What counts as evidence for a logical theory? The Australasion Journal of Logic, 16(7), 250-282. https://doi.org/10.26686/ajl.v16i7.5912

Hlobil, U. (2020). Limits of abductivism about logic. Philosophy and Phenomenological Research. https:// doi.org/10.1111/phpr.12707

Kouri Kissel, T. (2019). Logical instrumentalism and concatenation. Felsefe Arkivi, 51, 153-160. https:// doi.org/10.26650/arcp2019-5110

Martin, B. (2020). Identifying logical evidence. Synthese. https://doi.org/10.1007/s11229-020-02618-y

McSweeney, M. M. (2018). Logical realism and the metaphysics of logic. Philosophy Compass, 14, e12563. https://doi.org/10.1111/phc3.12563

Payette, G., \& Wyatt, N. (2018). Logical particularism. In J. Wyatt, N. J. L. L. Pedersen, \& N. Kellen (Eds.), Pluralisms in truth and logic (277-299). Palgrave Macmillan. https://doi.org/10.1007/978-3319-98346-2_12.

Priest, G. (2006). Doubt truth to be a liar. Clarendon Press.

Priest, G. (2014). Logical pluralism: Another application for chunk and permeate. Erkenntnis, $79($ suppl 2), 331-338.

Read, S. (2006). Monism: The one true logic. In D. DeVidi \& T. Kenyon (Eds.), A Logical approach to philosophy: Essays in honour of Graham Solomon. Springer.

Sagi, G. (2021). Logic as a methodological discipline. Synthese. https://doi.org/10.1007/s11229-02103223-3

Shapiro, S. (2014). Varieties of logic. Oxford University Press.

Van Benthem, J. (2008). Logical dynamics meets logical pluralism? The Australasian Journal of Logic. https://doi.org/10.26686/ajl.v6i0.1801.

Van Benthem, J. (2011). Logical dynamics of information and interaction. Cambridge University Press.

Van Benthem, J. (2014). Natural language and logic of agency. Journal of Logic, Language, and Information, 23(3), 367-382. https://doi.org/10.1007/s10849-014-9188-x

Williamson, T. (2013). Modal logic as metaphysics. Oxford University Press. https://doi.org/10.1093/acprof: oso/9780199552078.001.0001

Publisher's Note Springer Nature remains neutral with regard to jurisdictional claims in published maps and institutional affiliations. 